\title{
Photosensitive Poly(benzoxazole) via Poly(o-hydroxy azomethine) II. Environmentally Benign Process in Ethyl Lactate
}

\author{
Ken-ichi Fukukawa, Yuji ShIBASAKI, and Mitsuru UEDA ${ }^{\dagger}$ \\ Department of Organic \& Polymeric Materials, Graduate School of Science and Engineering, \\ Tokyo Institute of Technology, 2-12-1 O-okayama, Meguro-ku, Tokyo 152-8552, Japan
}

(Received January 23, 2004; Accepted March 11, 2004; Published June 15, 2004)

\begin{abstract}
The synthesis and photosensitivity of poly(o-hydroxyazomethine) (PHAM) from isophthalaldehyde (IPA) and 4,4'-(hexafluoroisopropylidene)bis(o-aminophenol) (6FAP) in an environmentally friendly solvent, ethyl lactate (EL) was investigated. Polycondensation of IPA and 6FAP proceeded in EL, giving PHAM with a number average molecular weight more than ten thousands. The solution of PHAM in EL showed a good stability for hydrolysis. The photosensitive film cast from the solution of PHAM and $25 \mathrm{wt} \%$ 1-\{1,1-bis[4-(2-diazo-1-(2H)-naphthalenone-5-sulfonyloxy)phenyl]methylethyl benzene (S-DNQ) in EL showed a sensitivity $\left(D_{0}\right)$ of $250 \mathrm{~mJ} / \mathrm{cm}^{2}$ and a contrast $\left(\gamma_{0}\right)$ of 2.5 with $436 \mathrm{~nm}$ light (g-line), respectively. A fine positive image featuring $10 \mu \mathrm{m}$ line-and-space pattern was observed on the film of the photoresist exposed to $200 \mathrm{~mJ} / \mathrm{cm}^{2}$ of g-line by the contact-printing mode. The positive image was successfully converted to a poly(benzoxazole) (PBO) pattern by thermal treatment. The optically estimated dielectric constant of the PBO is 2.76. [DOI 10.1295/polymj.36.489]

KEY WORDS Poly(benzoxazole)s / Poly(o-hydroxyazomethine) / Environmentally Friendly Process / High Temperature Material / Photosensitive Material / Photoresist / Low Dielectric Constants /
\end{abstract}

Poly(benzoxazole)s (PBOs) are an important class of macromolecules that have outstanding mechanical, thermal, and chemical properties. ${ }^{1-5}$ Photosensitive PBOs (PSPBOs) have been developed ${ }^{6-11}$ as alternative materials to photosensitive polyimides (PSPIs), which are widely used in constructing protection and insulation layers in semiconductor manufacturing. ${ }^{12}$ The precursors of PSPIs, poly(amic acid)s (PAAs) are very soluble in $2.38 \mathrm{wt} \%$ aqueous tetramethylammonium hydroxide (TMAHaq), an industrial standard aqueous alkaline developer. The dissolution rate, however, is too high to get a sufficient dissolution contrast between the exposed and unexposed areas. Thus, the dissolution rate of PAAs has to be reduced by either prebaking or post-exposure-baking. While these methods do not afford reliable dissolution contrasts, precursors of PSPBOs, poly $\left(o\right.$-hydroxyamide)s $(\mathrm{PHAs})^{6-11}$ have an appropriate dissolution rate in TMAHaq due to the presence of a phenolic $\mathrm{OH}$ moiety. $\mathrm{PBOs}$ are generally prepared from PHAs and poly(o-hydroxy imide) $)^{13,14}$ via thermal cyclization. Recently, a novel route of formulation for PSPBOs has been reported, based on poly (o-hydroxyazomethine)s (PHAMs) and diazonaphothoquinones (DNQs). ${ }^{15}$ Compared to the synthesis of PHA derived from dicarboxylic active diester and bis(o-aminophenol) derivatives, PHAM is an attractive precursor for PSPBO because of its facile synthesis from dialdehyde and bis (o-aminophenol) derivatives, and the leaving group in the synthesis of
PHAM is just water, environmentally advantageous to phenol in PHA synthesis. Furthermore, the direct photosensitive polymer formulation from the polymerization solution is possible by simply adding DNQ.

In industrial engineering an environmentally benign process for photosensitive polymer synthesis and formulation is desirable. The PHAM/DNQ system developed previously used $N$-methylpyrrolidone (NMP) as polymerization and casting solvent, and this well-known organic solvent including other amidic solvents like $\mathrm{N}, \mathrm{N}$-dimethylformamide (DMF), $\mathrm{N}, \mathrm{N}$-dimethylacetoamide (DMAc) in laboratory should be replaced in more environmentally friendly solvents such as propylene glycol monomethylacetate (PGMEA), $\gamma$-butyrolactone, cyclohexanone, and ethyl lactate (EL), designed to meet the demands of the electronics industry. Particularly, EL is non-toxic, biodegradable, and is made from renewable carbohydrates such as cornstarch, thus is so benign that the U.S. Food and Drug Administration approved its use in food products long ago. ${ }^{16}$

This report describes the environmentally friendly synthesis of PHAM from isophthalaldehyde (IPA) and 4,4'-(hexafluoroisopropylidene)bis(o-aminophenol) (6FAP) using EL as a polymerization solvent and the direct lithographic evaluation of the resist based on PHAM with 1-\{1-,1-bis[4-(2-diazo-1-(2H)naphthalenone-5-sulfonyloxy)phenyl]methylethyl\}benzene (S-DNQ) as a photosensitive compound in EL.

${ }^{\dagger}$ To whom correspondence should be addressed (E-mail: mueda@u.polymer.titech.ac.jp). 


\section{EXPERIMENTAL}

\section{Materials}

6FAP and IPA were recrystalized from hexane/tetrahydrofuran, and distilled water, respectively. Toluene was purified by atomospheric distillation from sodium metal and benzophenone ketyl. NMP was dried over calcium hydride, distilled under reduced pressure, and stored over $4-\AA$ molecular sieves. EL was purified by vacuum distillation from $4-\AA ̊$ molecular sieves and stored over the molecular sieves. SDNQ was kindly donated by Toyo Gosei Co., Ltd. and used without further purification. PI coating silicon wafer was kindly donated by Tokyo Ohka Kogyo Co., Ltd. The other reagents and solvents were used as received.

\section{Measurements}

The infrared resonance spectroscopy (IR) was taken with Horiba FT-210 spectrophotometer. The ${ }^{1} \mathrm{H}$ nuclear magnetic resonance (NMR) spectrum was recorded on BRUKER GPX300 (300 MHz) spectrometer. Thermogravimetric (TG) analysis was performed on Seiko thermal analyzer at a heating rate of $10^{\circ} \mathrm{C} / \mathrm{min}$. Number- and weight-average molecular weights $\left(M_{\mathrm{n}}\right.$ and $\left.M_{\mathrm{w}}\right)$ were determined by a gel permeation chromatography (GPC) with Tosoh HLC8120 GPC system equipped with polystyrene gel columns (TSK GELs; $\mathrm{GMH}_{\mathrm{HR}}-\mathrm{M}$, and $\mathrm{GMH}_{\mathrm{HR}}-\mathrm{L}$ ) at $40^{\circ} \mathrm{C}$ in DMF (containing with $0.01 \mathrm{M}$ of $\mathrm{LiBr}$ ) at a flow rate of $1.0 \mathrm{~mL} / \mathrm{min}$, calibrated with polystyrene standards. The film thickness on silicon wafers was measured by Veeco Instrument Dektak ${ }^{3}$ surface profiler. The field emission scanning electron microscope (SEM) was taken with HITACHI S-800 scanning electron microscope with $15 \mathrm{kV}$ accelerating voltage for imaging. Refractive indices of PBO films formed on quartz substrates were measured at a wavelength of $1.320 \mu \mathrm{m}$ at room temperature with Metricon model PC-2000 prism coupler. Using linearly-polarized laser with parallel (TE: transverse electric) and perpendicular (TM: transverse magnetic) polarization to the film plane, the in-plane $\left(n_{\mathrm{TE}}\right)$ and out-of-plane $\left(n_{\mathrm{TM}}\right)$ refractive indices and the film thickness of the samples were determined. The dielectric constant $(\varepsilon)$ at 1.0 $\mathrm{MHz}$ frequency was calculated from the equation as follows: $\varepsilon=1.10 n_{\mathrm{AV}}$, where $n_{\mathrm{AV}}$ is average refractive index (i.e. $\left.n_{\mathrm{AV}}=\left(2 n_{\mathrm{TE}}+n_{\mathrm{TM}}\right) / 3\right)$.

\section{Preparation of Poly(o-hydroxy azomethine) (PHAM) Solution}

A typical procedure for the synthesis of PHAM is as follows; into a $20 \mathrm{~mL}$ round bottom flask equipped with Dean-stark apparatus and a condenser were placed IAP $(1.465 \mathrm{~g}, 4 \mathrm{mmol}), 6 \mathrm{FAP}(0.537 \mathrm{~g}, 4$ $\mathrm{mmol})$, toluene $(3 \mathrm{~mL})$, and $\mathrm{EL}(3 \mathrm{~mL})$ under a stream of nitrogen. The receiver of dean-stark was filled with toluene for appropriate azeotropic condition. The polymerization was conducted at $130^{\circ} \mathrm{C}$ for $1 \mathrm{~h}$ under nitrogen. Then toluene was removed under reduced pressure to obtain PHAM solution in EL.

IR (film on $\mathrm{Si}$ wafer, $v, \mathrm{~cm}^{-1}$ ): $3421(\mathrm{OH}), 1627$ $(\mathrm{C}=\mathrm{N}), 1261\left(\mathrm{CF}_{3}\right) .{ }^{1} \mathrm{H}$ NMR $\left(\mathrm{DMSO}-d_{6}, \delta, \mathrm{ppm}\right)$ : 9.68 (brs, 2H), 8.73 (s, 2H), $8.57(\mathrm{~s}, 1 \mathrm{H}), 8.14$ (d, 2H), $7.61(\mathrm{t}, 1 \mathrm{H}), 7.14-6.98(\mathrm{~m}, 6 \mathrm{H})$

Synthesis of Poly[(o-4-tert-butoxycarbonyloxy)azomethine] (PtBAM)

To a solution of PHAM (polymer content: $1.0 \mathrm{~g}$, calculated as $1.52 \mathrm{mmol}$ of repeating unit), di-tert-butyl dicarbonate $(0.99 \mathrm{~g}, 4.56 \mathrm{mmol})$ and $N, N^{\prime}$-dimethylaminopyridine $(0.0024 \mathrm{~g}, 0.02 \mathrm{mmol})$ were added. After $1 \mathrm{~h}$, the resulting solution was poured into methanol/water mixed solvent $(1 / 1 \mathrm{in} \mathrm{v} / \mathrm{v}, 150 \mathrm{~mL})$ to precipitate the polymer. The yellow solid was filtered off followed by drying in vacuo at $80^{\circ} \mathrm{C}$ for $12 \mathrm{~h}$. The yield was $90 \%$.

IR $\left(\mathrm{KBr}, v, \mathrm{~cm}^{-1}\right): 2981(\mathrm{C}-\mathrm{H}), 1762(\mathrm{C}=\mathrm{O}), 1635$ $(\mathrm{C}=\mathrm{N}), 1276\left(\mathrm{CF}_{3}\right) .{ }^{1} \mathrm{H}$ NMR (DMSO- $\left.d_{6}, \delta, \mathrm{ppm}\right)$ : 8.55 (s, 2H), 8.47 (s, 1H), 8.04 (brs, 2H), 7.58 (brs, 1H), 7.37 (brs, 2H), 7.29-7.14 (m, 4H), 1.30 (s, 18H).

\section{Dissolution Rate}

To formulate a photosensitive polymer, S-DNQ (as $25 \mathrm{wt} \%$ of the total solids, at maximum) was added directly to a $15 \mathrm{wt} \%$ of polymerization solution. The polymer film prepared by spin-coating onto a PI-coated silicon wafer, was prebaked at $80^{\circ} \mathrm{C}$ for $1 \mathrm{~min}$, exposed to a UV light at $436 \mathrm{~nm}$ wavelength by a filtered super-high pressure mercury lamp, developed with a $2.38 \mathrm{wt} \%$ TMAHaq solution at $25^{\circ} \mathrm{C}$, and rinsed in water. The variations of the film thickness on the silicon wafer between the exposed and unexposed area were measured against developing time by Dektak ${ }^{3}$ surface profiler.

\section{Photosensitivity}

A UV light at wavelength of $436 \mathrm{~nm}$ from the filtered super-high pressure mercury lamp was radiated to a $1.7-\mu \mathrm{m}$-thick photosensitive polymer film on a PI coated silicon wafer, which was baked at $80^{\circ} \mathrm{C}$ for $2 \mathrm{~min}$, developed with the $2.38 \mathrm{wt} \%$ of TMAHaq at $25^{\circ} \mathrm{C}$, and rinsed in water. A characteristic curve was obtained by plotting the normalized film thickness against the exposure dose $\left(0-300 \mathrm{~mJ} / \mathrm{cm}^{2}\right)$. Image-wise exposure through a mask was carried out in a contact-printing mode. 
<smiles>CC(C)c1cc(C=O)cc(C(=O)C=O)c1</smiles>

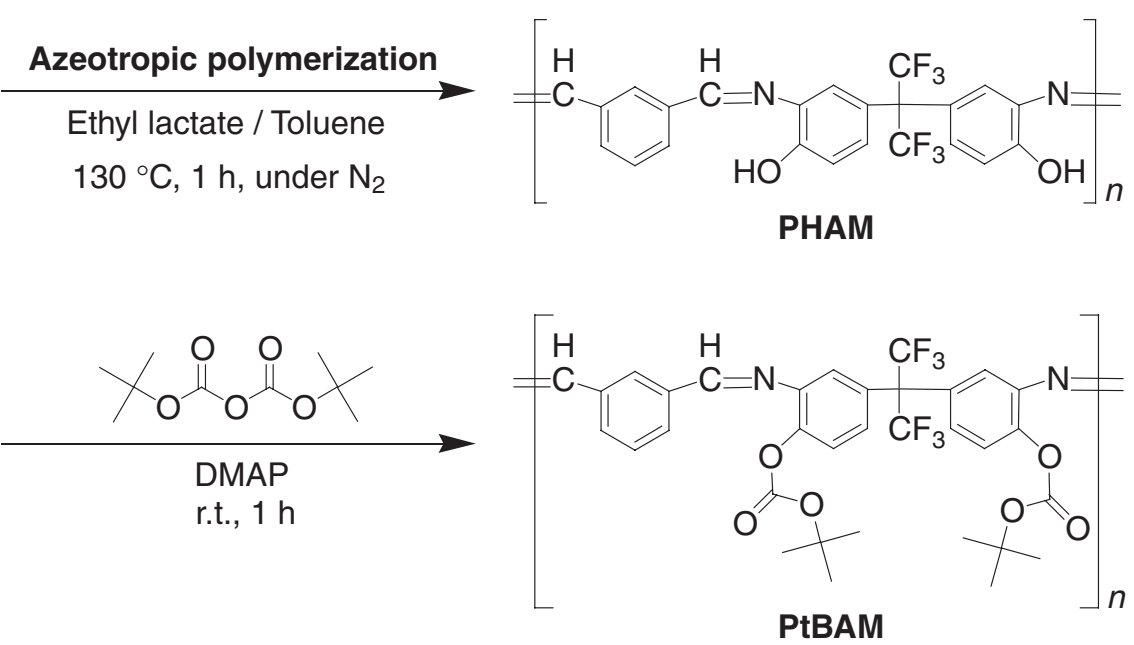

Scheme 1. Synthesis of PHAM and PtBAM.
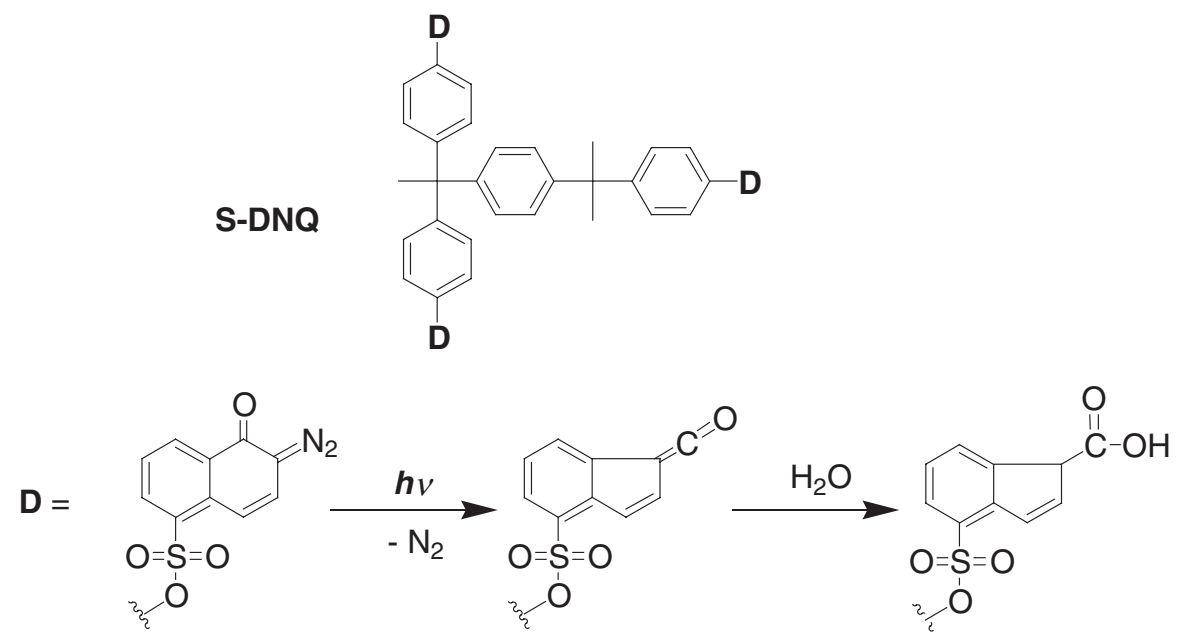

Dissolution inhibiting part

Soluble in TMAHaq

Scheme 2. Structure of photosensitive dissolution inhibitor, S-DNQ.

\section{Thermal Treatment}

Both PAHM film and photosensitive PHAM film composed of S-DNQ on a substrate (silicon wafer or quartz plate) was subjected to thermal treatment with a hotplate in a dark room. The elevating temperatures were set gradually as $150^{\circ} \mathrm{C}$ for $0.5 \mathrm{~h}, 200^{\circ} \mathrm{C}$ for $0.5 \mathrm{~h}$ and $350^{\circ} \mathrm{C}$ for $1 \mathrm{~h}$ in air.

\section{RESULTS AND DISCUSSION}

\section{Polymer Syntheses and Their Stabilities in Solutions}

As described in Introduction, an environmentally benign process for a photosensitive polymer formulation should be established. One of the common sol- vents in photoresist formulation, EL, was selected for the polymerization and casting films in stead of amidic solvent such as NMP. The polycondensation of IAP with 6FAP was carried out in EL/toluene at $130^{\circ} \mathrm{C}$ for $1 \mathrm{~h}$ under azeotropic condition (Scheme 1). Toluene was used to exclude generating water out of the solution during the polymerization so that toluene was removed under reduced pressure. The polycondensation proceeded smoothly in EL as the same as in NMP, giving PHAM with $M_{\mathrm{n}}$ above $10^{4}$.

To elucidate the solution stability, the polymerization solution in a sealed bottle was stored at $10^{\circ} \mathrm{C}$ or $30^{\circ} \mathrm{C}$ for a set time after removing toluene, while the same sample in an open bottle was placed at room temperature (around $20^{\circ} \mathrm{C}$ ) for a comparison. GPC 
Table I. Solution stability of PHAM and following tBoc protection (PtBAM)

\begin{tabular}{|c|c|c|c|c|c|c|c|}
\hline \multirow[b]{2}{*}{ Polymer $^{\mathrm{a}}$} & \multirow[b]{2}{*}{ Solvent ${ }^{\mathrm{b}}$} & \multicolumn{2}{|c|}{ Storage } & \multirow[b]{2}{*}{$\begin{array}{c}\text { Yield }^{\mathrm{d}} \\
(\%)\end{array}$} & \multicolumn{3}{|c|}{$\mathrm{GPC}^{\mathrm{e}}$} \\
\hline & & $\begin{array}{c}\text { Condition }^{\mathrm{c}} \\
\left({ }^{\circ} \mathrm{C}\right)\end{array}$ & $\begin{array}{l}\text { Period } \\
\text { (d) }\end{array}$ & & $\begin{array}{c}M_{\mathrm{n}} \\
\left(\times 10^{3}\right)\end{array}$ & $M_{\mathrm{w}} / M_{\mathrm{n}}$ & Profile \\
\hline E-0 & EL & - & 0 & 93 & 11.3 & 2.1 & uni \\
\hline E-10-7 & EL & 10 & 7 & 93 & 12.2 & 2.6 & uni \\
\hline E-10-21 & EL & 10 & 21 & 82 & 11.2 & 2.2 & uni \\
\hline E-30-7 & EL & 30 & 7 & 96 & 15.6 & 2.5 & uni \\
\hline E-O-3 & EL & open & 3 & 79 & 6.0 & 1.6 & multi \\
\hline $\mathrm{N}-0$ & NMP & - & 0 & 96 & 15.2 & 2.2 & uni \\
\hline N-10-7 & NMP & 10 & 7 & 96 & 15.5 & 2.5 & uni \\
\hline $\mathrm{N}-\mathrm{O}-3$ & NMP & open & 3 & 94 & 7.5 & 1.2 & multi \\
\hline
\end{tabular}

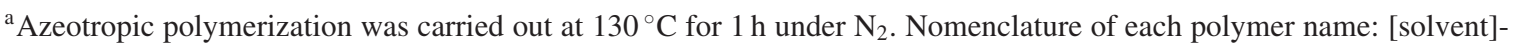
[store condition]-[store day]. ${ }^{\mathrm{b}}$ After the polymerization toluene was removed in vacuo. ${ }^{\mathrm{c}}$ "Open" means storing the bottle in ambient temperature $\left(20^{\circ} \mathrm{C}\right)$ without sealing. ${ }^{\mathrm{d}}$ Yield was determined after tBoc protection (PtBAM). ${ }^{\mathrm{e}} \mathrm{GPC}$ was conducted in DMF at $40^{\circ} \mathrm{C}$ with polystyrene standard calibration.

measurement (eluent: DMF at $40^{\circ} \mathrm{C}$ ) was utilized for determining molecular weight as the function of time to evaluate a shelf life of the PHAM solution. In order to prevent the unfavorable hydrolysis, a protection of hydroxyl groups in PHAM using di-tert-butyl dicarbonate was performed before the GPC measurement. The shelf life in NMP was also investigated and the results are summarized in Table I. The $M_{\mathrm{n}}$ s of PHAM in EL and NMP solutions decrease at $20^{\circ} \mathrm{C}$ in open state for $3 \mathrm{~d}$ (E-O-3 and N-O-3), which suggests moisture taken into those solvents induces the hydrolysis of PHAM. On the other hand, the PHAM in EL solution is stable for a long time at $10^{\circ} \mathrm{C}$ in the sealing state (E-0, E-10-7, and E-10-21) as similar behavior of that in NMP (N-0 and N-10-7). The $M_{\mathrm{n}}$ of PHAM in EL solution increased at $30^{\circ} \mathrm{C}$ for $7 \mathrm{~d}$ (E-30-7) and the precipitation of the polymer was observed. This result indicates the post polycondensation of PHAM. Therefore, the precaution for the protection of the polymerization solution from moisture should be taken, and the storing PHAM solution in EL at $10^{\circ} \mathrm{C}$ is important for a reliability of the industrial use.

\section{Lithographic Evaluation}

The resist was formulated by adding S-DNQ to the polymerization solution to clarify a dissolution behavior in both exposed and unexposed areas. The effect of S-DNQ loading on the dissolution rate in the developer (2.38 wt \% TMAHaq) was studied. The film spincast on a PI-coating-silicon-wafer was prebaked at $80^{\circ} \mathrm{C}$ for $1 \mathrm{~min}$, and then exposed to a $436 \mathrm{~nm}$ light (g-line, $300 \mathrm{~mJ} / \mathrm{cm}^{2}$ ) because the optical absorption edge of PHAM film reaches around $420 \mathrm{~nm} .{ }^{15}$ The dissolution rate in both the exposed and unexposed area was estimated from the each film thickness after development. The results are shown in Figure 1. The dissolution rate of the exposed area decreases gradually with increasing S-DNQ contents, and the difference

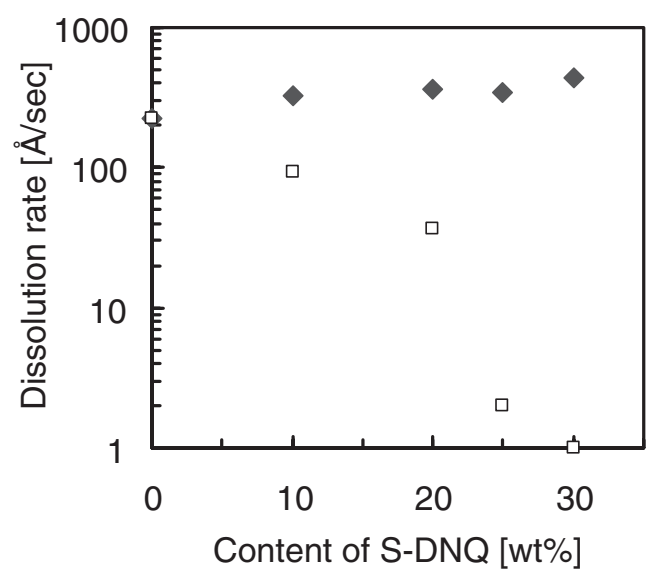

Figure 1. Plots of dissolution rate of photosensitive PHAM $v s$. S-DNQ loading in the exposed area $(\bullet)$ and unexposed area ( $\square$ ). The PHAM film was prebaked at $80^{\circ} \mathrm{C}$ for $1 \mathrm{~min}$, exposed $300 \mathrm{~mJ} / \mathrm{cm}^{2}$ with g-line, and then developed with $2.38 \mathrm{wt} \%$ TMAHaq at $25^{\circ} \mathrm{C}$.

in the dissolution rate between the two areas reaches about 200 times with $25 \mathrm{wt} \%$ S-DNQ loading.

Generally, a trace of solvents remains in a resist film, which increases the mobility of polymer in the film. Thus, the effect of prebake temperature was investigated (Figure 2). Since the decomposition temperature of DNQ is around $120^{\circ} \mathrm{C}$, the prebake temperature was set in a range of 70 to $110^{\circ} \mathrm{C}$. The dissolution rates among the regions are gradually decreased with increasing the prebake temperature. The optimization was determined at $80^{\circ} \mathrm{C}$, showing a difference of the solubility almost 200 times.

On the basis of these preliminary investigations, the photosensitive curve of the PHAM film (film thickness: $1.7 \mu \mathrm{m}$ ) was plotted as shown in Figure 3. The resist film was formulated by the addition of $25 \mathrm{wt} \%$ S-DNQ into the polymerization solution, followed by spin-casting, prebaking at $80^{\circ} \mathrm{C}$ for $2 \mathrm{~min}$, and then developing with $2.38 \mathrm{wt} \%$ TMAHaq. From 


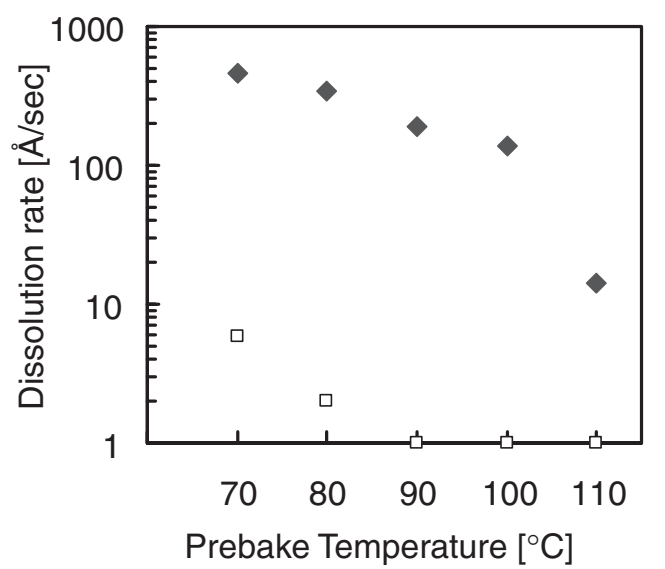

Figure 2. Plots of dissolution rate of photosensitive PHAM vs. prebake temperature from 70 to $110^{\circ} \mathrm{C}$ in the exposed area $(\checkmark)$ and unexposed area $(\square)$. The baking time of the film was $1 \mathrm{~min}$, followed by $300 \mathrm{~mJ} / \mathrm{cm}^{2}$ of exposure by g-line and development with $2.38 \mathrm{wt} \%$ TMAHaq at $25^{\circ} \mathrm{C}$.

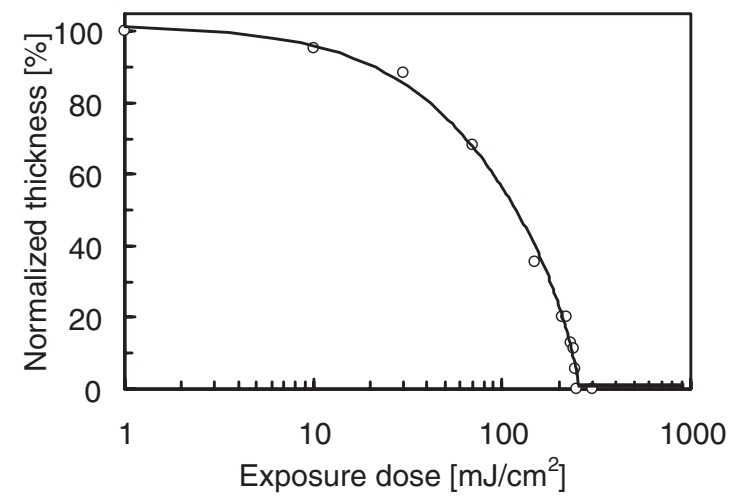

Figure 3. Exposure characteristic curve for photosensitive PHAM with $25 \mathrm{wt} \%$ of S-DNQ. The PHAM film was prebaked at $80^{\circ} \mathrm{C}$ for $2 \mathrm{~min}$ (film thickness: $1.7 \mu \mathrm{m}$ ), exposed with g-line, and then developed with $2.38 \mathrm{wt} \%$ TMAHaq at $25^{\circ} \mathrm{C}$ for $90 \mathrm{~s}$. A characteristic curve was obtained by plotting the normalized film thickness against the exposure dose, showing sensitivity $\left(D_{0}\right)$ and contrast $\left(\gamma_{0}\right)$ were $250 \mathrm{~mJ} / \mathrm{cm}^{2}$ and 2.5 , respectively.

the photosensitive curve, the sensitivity and contrast were determined as $250 \mathrm{~mJ} / \mathrm{cm}^{2}$ and 2.5 , respectively. Figure 4 shows a scanning electron micrograph of the contact-printed positive image after an exposure of $200 \mathrm{~mJ} / \mathrm{cm}^{2}$. A clear $10 \mu \mathrm{m}$ line-and-space pattern is observed when a $2.0-\mu \mathrm{m}$-thick film was used.

\section{Thermal Treatment}

The PHAM film on the silicon wafer was cured at

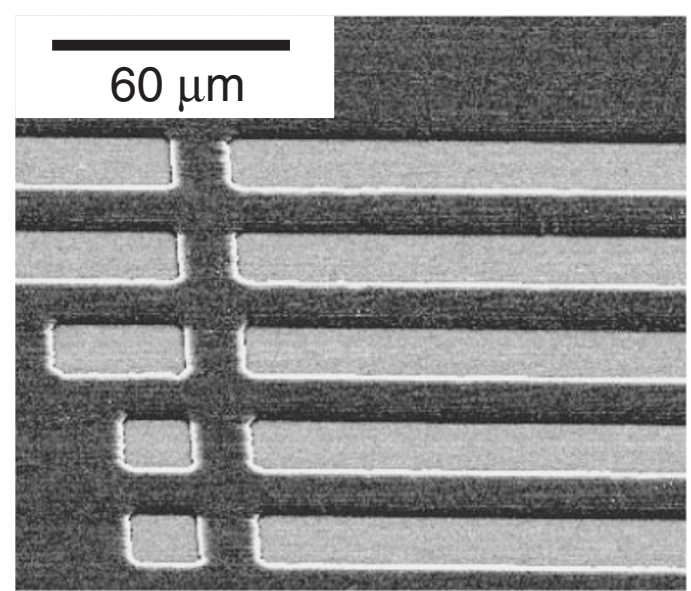

Figure 4. SEM image of positive pattern PHAM with $25 \mathrm{wt} \%$ of S-DNQ. Lithographic condition: prebake was $80^{\circ} \mathrm{C}$; film thickness was $2.0 \mu \mathrm{m}$ on PI-coating silicon-wafer; exposure dose was $200 \mathrm{~mJ} / \mathrm{cm}^{2}$ of g-line by contact-mode printing; development was performed with $2.38 \mathrm{wt} \%$ TMAHaq at $25^{\circ} \mathrm{C}$ for $90 \mathrm{~s}$, followed by rinsing with water.

$100^{\circ} \mathrm{C}$ for $0.5 \mathrm{~h}, 200^{\circ} \mathrm{C}$ for $0.5 \mathrm{~h}$, and $350^{\circ} \mathrm{C}$ for $1 \mathrm{~h}$ under air (Scheme 3). In the IR spectrum, the characteristic absorption at $1627 \mathrm{~cm}^{-1}$ due to oxazole ring was appeared, and the absorption at $3421 \mathrm{~cm}^{-1}$ corresponding to the hydroxyl group in PHAM was disappeared, indicating a transformation of PHAM into the corresponding $\mathrm{PBO} .{ }^{15}$ In the same curing treatment, the photosensitive PHAM film containing S-DNQ on silicon wafer was transformed into the PBO film, where no crucial deformation of the image is observed as shown in Figure 5.

TG analyses of these two cured PBO films from PHAM (PBO-I) and from photosensitive PHAM film (PBO-II) were performed under nitrogen atmosphere. The $1 \mathrm{wt} \%$ weight loss temperature was observed at $480^{\circ} \mathrm{C}$ for PBO-I and $430^{\circ} \mathrm{C}$ for PBO-II as shown in Figure 6. The lower decomposition temperature of PBO-II might be attributed to the side products by decomposition of S-DNQ because more than half of that was still remained in the film at $350^{\circ} \mathrm{C}$ checked by TG of S-DNQ in nitrogen.

\section{Measurement of Dielectric Constants}

One might concern the dielectric constant of the patterned PBO film because the residue of S-DNQ would enlarge the dielectric constant $(\varepsilon)$ even the polymer matrix has inherently low dielectric charac-

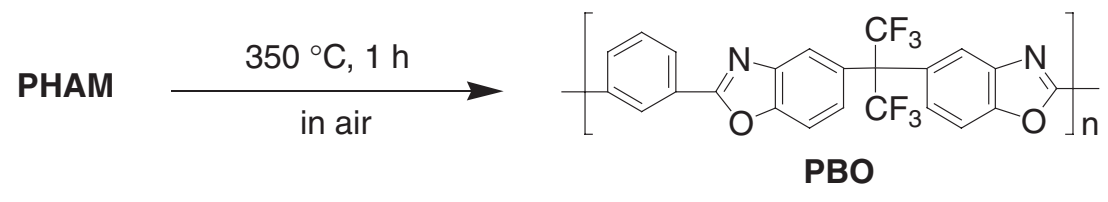

Scheme 3. Thermal conversion into PBO. 


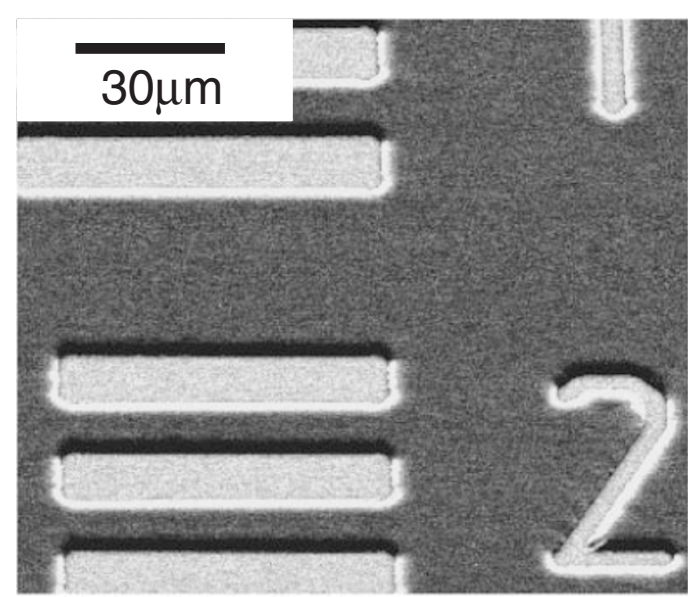

Figure 5. SEM image of photosensitive PBO with $10 \mu \mathrm{m}$ lineand-space. Thermal treatment was carried out by elevated heating as $100^{\circ} \mathrm{C}$ for $0.5 \mathrm{~h}, 200^{\circ} \mathrm{C}$ for $0.5 \mathrm{~h}$ and $350^{\circ} \mathrm{C}$ for $1 \mathrm{~h}$ in the air.

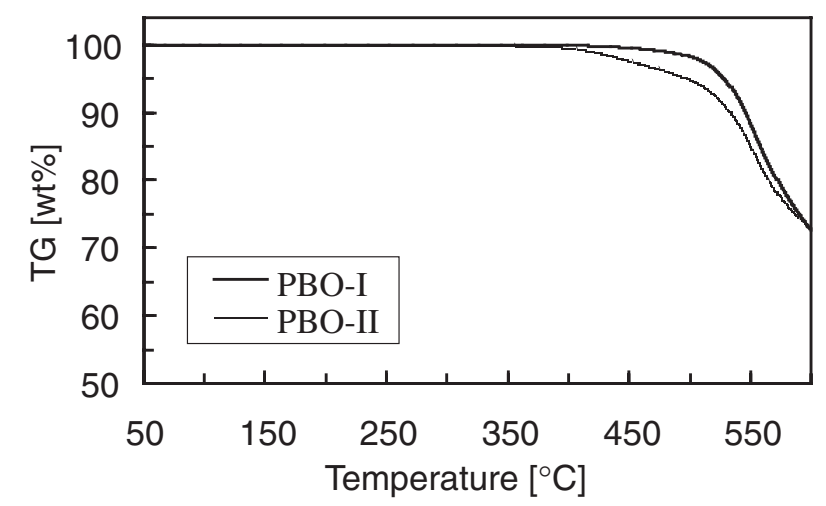

Figure 6. TGs of PBO-I and PBO-II films. A film of PBO-I was prepared from PHAM only, while PBO-II was from PHAM containing $25 \mathrm{wt} \%$ of S-DNQ, followed by the thermal treatment.

ter. To clarify this point, the dielectric constants of PBO-I and PBO-II film were estimated from their refractive indices. These PBO films were prepared by spin-casting on quartz plate from each solution in EL and cured at $300^{\circ} \mathrm{C}$ for $1 \mathrm{~h}$. As shown Table II, the $\varepsilon$ values of these films were very similar $(2.74$ and 2.76 at $1 \mathrm{MHz}$ ), which indicated that the low dielectric nature was realized even using photosensitive PBO film containing the side products produced by thermal decomposition of S-DNQ.

Table II. Refractive indices and dielectric constants of PBO-I and PBO-II

\begin{tabular}{lccccc}
\hline Film & $\begin{array}{c}\text { Thickness } \\
(\mu \mathrm{m})\end{array}$ & $n_{\mathrm{TE}}{ }^{\mathrm{a}}$ & $n_{\mathrm{TM}}{ }^{\mathrm{b}}$ & $n_{\mathrm{AV}}{ }^{\mathrm{c}}$ & $\varepsilon^{\mathrm{d}}$ \\
\hline PBO-I & 5.5 & 1.5784 & 1.5748 & 1.5772 & 2.74 \\
PBO-II & 7.9 & 1.5849 & 1.5786 & 1.5828 & 2.76 \\
\hline
\end{tabular}

${ }^{\mathrm{a}}$ In-plane refractive index. ${ }^{\mathrm{b}}$ Out of plane refractive index. ${ }^{\mathrm{c}}$ Average refractive index; $n_{\mathrm{AV}}=\left(2 n_{\mathrm{TE}}+n_{\mathrm{TM}}\right) / 3$. ${ }^{\mathrm{d}}$ Optically estimated dielectric constant; $\varepsilon=1.10 n_{\mathrm{AV}}{ }^{2}$.

\section{CONCLUSIONS}

PHAM was synthesized by azeotropic polycondensation of IPA with 6FAP in EL and toluene. The PHAM solution in EL which is stable for the hydrolysis even without isolation procedure was converted to the photoresist by the addition of S-DNQ. Its sensitivity $\left(D_{0}\right)$ and contrast $\left(\gamma_{0}\right)$ were $250 \mathrm{~mJ} / \mathrm{cm}^{2}$ and 2.5 with $436 \mathrm{~nm}$ light, respectively. After exposure of the light and development with TMAHaq, the positive image of PHAM film was patterned with $10 \mu \mathrm{m}$ line-andspace, and then converted into PBO film without deformation by thermal treatment at $350^{\circ} \mathrm{C}$ for $1 \mathrm{~h}$ in the air. This photosensitive PBO exhibits low dielectric constant, 2.76 at $1 \mathrm{MHz}$ estimated from refractive index even containing S-DNQ residue. Thus, these results open the reliable utility of photosensitive $\mathrm{PBO}$ as a low- $k$ material prepared directly from PHAM solution with S-DNQ in EL, environmentally friendly solvent.

\section{REFERENCES}

1. C. J. Arnold, J. Polym. Sci., Part D: Macromol. Rev., 14, 265 (1979).

2. Y. Imai, K. Itoya, and M. Kakimoto, Macromol. Chem. Phys., 201, 2251 (2000).

3. G. Maier, Prog. Polym. Sci., 26, 3 (2001).

4. H. Zhang, R. J. Farris, and P. R. Westmoreland, Macromolecules, 36, 3944 (2003).

5. T. Kitagawa, K. Yabuki, and R. J. Young, Polymer, 42, 2101 (2001).

6. D. N. Khanna and W. H. Mueller, Polym. Eng. Sci., 29, 954 (1989).

7. T. Yamaoka, N. Nakajima, and K. Koseki, J. Polym. Sci., Part A: Polym. Chem., 28, 2517 (1990).

8. M. Ueda, K. Ebara, and Y. Shibasaki, J. PhotoPolym. Sci. Technol., 16, 237 (2003).

9. K. Ebara, Y. Shibasaki, and M. Ueda, J. PhotoPolym. Sci. Technol., 16, 287 (2003).

10. K. Ebara, Y. Shibasaki, and M, Ueda, Polymer, 44, 333 (2003).

11. C. S. Hong, M. Jikei, R. Kikuchi, and M. Kakimoto, Macromolecules, 36, 3174 (2003).

12. M. K. Ghosh and K. L. Mittal, Ed., "Polyimides Fundamentals and Applications," Marcel Decker, New York, N.Y., 1996.

13. G. L. Tullos, J. M. Powers, S. J. Jeskey, and L. J. Mathias, Macromolecules, 32, 3598 (1999).

14. S. L. Hsu and M. H. Fan, Polymer, 45, 1101 (2004).

15. K. Ebara, Y. Shibasaki, and M. Ueda, J. Polym. Sci., Part A: Polym. Chem., 40, 3399 (2002).

16. See; http://www.ipd.anl.gov/biotech/programs/chemicals/ ethyl-lactate.html 